\title{
The Notion of Entropy in Economic Analysis: The Classical Examples and New Perspectives
}

\author{
Liudmyla Yu. VOZNA ${ }^{1}$ \\ DOI 10.1515/JHEEC-2016-0001
}

\begin{abstract}
This article deals with the notion of entropy in its applicability to economics. It considers some classical cases in which entropy is used, such as the labor concept of Podolinsky and the bioeconomics of Georgescu-Roegen. This article also attempts to apply the concept of entropy to the analysis of market structures in the perfect competition model. The article asserts that if we compare different entropy concepts with the main characteristics of a market with perfect competition, we must conclude that the latter is a structure with the maximum level of entropy. This means, in particular, that a market with perfect competition is totally disorganized and chaotic. The main conclusions of the article concern questions about system stability, complexity and the phenomenon of a living system, and, thus, give a real example of the applicability of the synergetic paradigm in economics.
\end{abstract}

Keywords:

JEL Classification: entropy, the second law of thermodynamics, uncertainty, market structure, perfect competition, disorder, complexity $B 4, D 41, D 8$

\section{Introduction}

The notion of entropy is primarily associated with the Second Law of Thermodynamics. This law asserts that a natural thermodynamic process runs only in one direction, and is not reversible. For example, heat always flows spontaneously from hotter to colder bodies, and never the other way, unless external work is performed on the system. In terms of entropy, the Second Law of Thermodynamics states that the entropy of an 
isolated system never decreases, because isolated systems always evolve towards thermodynamic equilibrium - that is, towards a state with maximum entropy.

One of the first economists who used this physical law in economic analysis was the Ukrainian-Russian scholar Sergei Podolinsky. In his work Human Labor and its Relationship with Energy Distribution, published for the first time in 1880, he proposed a new definition of human labor on the basis of the Second Law of Thermodynamics. However, his contemporaries did not understand and did not appreciate his new approach. Nowadays, unlike Podolinsky's times, the application of the notion of entropy in economic research is not unusual. First of all it is necessary to mention the RomanianAmerican economist Nicholas Georgescu-Roegen and his work The Entropy Law and the Economic Process (1971), and also such schools of heterodox economics as ecological economics and thermoeconomics. Besides, recent decades have been characterized by the large-scale penetration of systems theory and synergetics in economic science, and also by the growing popularity of econophysics. This tendency gave real examples of the use of the concept of entropy in economic research, and expanded the spectrum of this use, so that it covers not only the classical concept associated with the Second Law of Thermodynamics but also other concepts of entropy such as Shannon entropy (see e.g. Dima et al., 2014).

Nevertheless it is still too early to speak about the victory of the interdisciplinary approach in modern economics, particularly because traditional economics textbooks do not actually use the concept of entropy to characterize economic systems (structures) and phenomena. In this article I propose to use the notion of entropy to analyze a neoclassical model presented by mainstream economics textbooks, namely the market with perfect competition. In doing this we should conclude that it is impossible that a perfectly competitive market exists. Although economists recognize the unreality of such a market structure from an empirical point of view, the application of the entropy concept helps us to reach this conclusion from a methodological point of view too.

In summary, the article consists (in addition to the Introduction and the Conclusion) of three parts. The first part (Section 2) contains a brief review of the labor concept of Podolinsky and the bioeconomics of Georgescu-Roegen, which are the classical examples of the use of the Second Law of Thermodynamics in economics. Here, my goal is not to analyze these conceptions from all possible points of view, nor to review their critics, but to use these examples, first, to illustrate the limitations of the orthodox approach and the use of interdisciplinary work in economic analysis and, secondly, to help to give a better understanding of the meaning of entropy in its connection with the laws of thermodynamics.

The next part of the article is dedicated to the characteristics of entropy itself. Although entropy is associated primarily with the Second Law of Thermodynamics, there are today a great number of different entropies (the entropies of Boltzmann, Gibbs, Clausius, Shannon, Kullback, Hardy, Tsallis, etc.), and there is no single and perfect definition (Panchenkov, 2007, p. 153). For this reason it is necessary to be extremely careful when using the notion of entropy in economic analysis and, thus, to make certain statements. It is noteworthy that Nicholas Georgescu-Roegen, whose name is the one primarily associated with the application of the notion of entropy in modern economics, also emphasized that 'the concept of entropy is so involved that even physicists may go wrong with it' $(1986$, p. 3$)$. So, in this part of the article, the main different and comparatively 
simple interpretations of entropy are proposed, to make it possible to give a clear application of the concept of entropy in the analysis of a market with perfect competition. Finally, in the third part of the article I attempt to apply the concept of entropy to the analysis of market structures in the example of the perfect competition model. Here I therefore compare different concepts of entropy with the main characteristics of a market with perfect competition, and conclude that such a market is a structure with the maximum level of entropy. However, whereas maximum entropy means the death of a system, as a system or a structure, a perfectly competitive market cannot exist. Hence, on the one hand, I try to demonstrate in the article how the application of the concept of entropy complements the analysis of certain economic phenomena, making them more obvious or, conversely, unrealizable, while, on the other hand, the example of a market with perfect competition is also capable of enriching systems theory and the synergetic paradigm insofar as it concerns the problems of system stability, complexity and living systems.

\section{The Second Law of Thermodynamics in the "law of Podolinsky" and in modern economics}

One of the first economists who used the Second Law of Thermodynamics in economic analysis was the Ukrainian-Russian scholar Sergei Podolinsky. Sergei Podolinsky was born in 1850 and died in 1891 in Kiev. He had a medical education and also dealt with political economy, physics, and philosophy. The diversity of his knowledge is reflected in his approach to economic analysis and in general his multidisciplinary character. So, in his economic work Human Labor and Its Relationship with Energy Distribution, published for the first time in Russian in the journal Slovo (St. Petersburg) in 1880, he proposed the new definition of human labor on the basis of the laws of thermodynamics.

In the book mentioned above, Podolinsky starts his analysis from the examination of energy and the law of energy conservation. He also regards the Sadi (Nicolas Léonard) Carnot's research dealing with the operation of heat engines and, thus, he actually regards the Second Law of Thermodynamics.

Using the principles of thermodynamics, Podolinsky asserts that the role of the internal energy of the Earth and the energy of the Sun in the energy budget of the Earth with time decreases (Podolyns'ky, 2000). The part of the energy, which the Earth receives from the Sun, dissipates and thus transforms into inferior (unproductive) forms. But part of this energy is accumulated by animals and plants, and therefore transforms into superior forms. Since animals and plants are capable of accumulating the sunny energy, human activities related to crop production and livestock (agriculture) contribute to the accumulation of the productive energy of the Earth. So Podolinsky proposes the new definition of human labor. According to his definition, (human) labor is such a consumption of mechanical and psychical work, accumulated in an organism, which results in the growth of transformed energy on the Earth's surface. (In this definition, we must understand 'work, accumulated in an organism' as an 'energy, accumulated in an organism'. 'Transformed energy' is the energy of superior quality.)

In opinion of Podolinsky, the most productive labor is agricultural. So with this point he is very close to the ideas of physiocrats. But his definition of labor was really innovative. 
In general, according to Podolinsky, human labor gives possibility to accumulate additional energy on the Earth and to prevent the dissipation of energy (counteracts entropy).

Podolinsky also participated in the socialistic movement of Russian Empire and was an admirer of Karl Marx. He sent Marx the French version of his work (Le travail humain et la conservation de l'énergie), asking his opinion on the issue and said that he wrote this work under the influence of The Capital. Marx responded favorably to the work of Podolinsky and asked Friedrich Engels to express his opinion. In his letters to Marx, Engels pointed to the value of Podolinsky's discovery but considered its economic conclusions wrong. In the opinion of Engels, Podolinsky's 'real discovery is that human labor is capable of retaining solar energy on the earth's surface and harnessing it for a longer period than would otherwise have been the case'; but Podolinsky wanted to use this argument to prove socialism and, thus, mixed physical phenomena with economic ones ('economics should not be mixed up with physics') (Burketta \& Fosterb, 2008; Korniychuk, 2000; about the Podolinsky's energy analysis from the Marxist framework's point of view see e.g. Martinez-Alier \& Naredo, 1982; Munda, 2016, p. 192).

The main work of Podolinsky was published in Russian, French, German, and Italian. But contemporaries of the Ukrainian scholar did not appreciate it. This fact greatly depresed Podolinsky. The modern estimate of Podolinsky's views is ambiguous. Some scholars write that 'Engels's criticisms of Podolinsky are found to be quite justified from both political-economy and ecological perspectives' (Burketta \& Fosterb, 2008). However, many modern Ukrainian and Russian economists are deeply interested in the scientific heritage of Podolinsky, and his conclusion about the ability of human labor to prevent the growth of entropy (or to increase land productivity and, thus, accumulation of useful energy on the Earth) they name as the law of Podolinsky (Korniychuk, 2000).

In modern economics, the use of the notion of entropy is primarily associated with the Romanian-American economist Nicholas Georgescu-Roegen and his work The Entropy Law and the Economic Process (1971).

Like Podolinsky, Georgescu-Roegen's analysis of entropy in its relation to human economic activities builds on the basic laws of thermodynamics. In particular, he notes that:

Received thermodynamic theory is founded on four laws - the first, total energy is constant; the second, in actuality entropy steadily increases; the third, the absolute zero of temperature cannot be reached; and the 'zeroth' (so termed because it was added last but being the most fundamental it had to precede 'the first') which states that thermodynamic equilibrium is transitive condition. (Georgescu-Roegen, 1986, p. 6).

However, Georgescu-Roegen's visual angle for the assessment of human economic activity in relation to entropy is absolutely different from S. Podolinsky's. So, if according to Podolinsky, human labor gives the possibility to accumulate additional energy on the Earth and to prevent the dissipation of energy (counteracts entropy), according to Georgescu-Roegen, humankind with its economic activity is the most significant contributor to entropic degradation by the increasing rates of extraction of natural resources and elimination of wastes into the environment.

To some extent, the mentioned difference can be explained by the fact that Podolinsky, regarding human labor, meant first of all labor in the field of agriculture, whereas Georgescu-Roegen criticized the model of economic activity (growth), typical for the era 
of industrialism. In contrast to the agrarian society, which mainly has characteristics of a closed and static system, industrial systems are mainly open and dynamic, and the longterm economic growth is regarded as a crucial macroeconomic feature and a goal of industrially developed countries.

Furthermore, during the period preceding the publication of Georgescu-Roegen's works dealing with entropy, economists, influenced by the Great Depression, tried to elaborate the models of long-run growth associated with a smooth and uninterrupted (crisis-free) functioning of an economy. They could be models within the framework of Keynesian economics using an investment multiplier (Harrod-Domar model), or they could be neoclassical models, in which technological progress was regarded as a crucial factor of long-run economic growth (Robert Solow model). Nevertheless, despite the distinction in methodological approaches, the different models of growth had something in common, namely the intention to design a special 'golden' formula (function, mechanism, proportion) to ensure the steady growth of an advanced capitalist economy. In some ways, such a formula in economics recalls a hypothetical perpetual motion machine in mechanics. As a perpetual motion machine can do work indefinitely without an energy source, the mentioned 'golden' ratio (as a warranted growth rate in the Harrod-Domar model or the golden rule of capital accumulation in Solow's model, etc.) can help an economy grow smoothly without recessions.

In mechanics, the idea of a perpetual motion machine was disproved by the law of entropy. Similarly, Georgescu-Roegen, using the thermodynamic theory, criticized the numerous theories of growth that were popular at that time. In his opinion, although all production processes do not obey the same economic laws, all economic processes, like biological processes, are subject to the Entropy Law. So, in accordance with Gowdy and Mesner, 'invoking the Second Law of Thermodynamics, Georgescu-Roegen incorporates the idea of entropic degradation as a fundamental constraint on all economic activity' (1998, p. 146).

Indeed, although industrial capitalism must be regarded as a dynamic and growing system, it also depends on limited material resources, whose creation (production) is determined by the Earth as a geological and ecological system. Strictly speaking, the Earth as an ecosystem with its resources is not a closed system, because it constantly receives solar energy; however, from the standpoint of obtainment of mineral and energy resources such as gas, oil, and coal, humankind must regard the Earth as a closed (isolated) system. Even if we imagine that with time such resources can be reproduced naturally, it takes an incredibly long period of time in comparison with a human life as well as the existence of mankind in general. In this way, it is no coincidence that Georgescu-Roegen emphasized the anthropomorphic aspect of thermodynamics laws and pointed to 'the finite human nature' (Georgescu-Roegen, 1986, p. 5).

With his skepticism toward the growth models, including the Solow's, and considering the unlimited progress and the power of technology without limits as a myth (GeorgescuRoegen, 1975), in his own model of production Georgescu-Roegen defined a technology as viable if and only if it can maintain the corresponding material structure that supports its resource flows and sustaining functions and that can consequently support the human species indefinitely under current environmental conditions (Gowdy \& Mesner, 1998, p. 149-150). 
It is symbolic that the principal Georgescu-Roegen work on entropy was published in 1971 , that is, at the peak of the relatively long economic prosperity of the sixties and almost on the eve of the global energy crisis of the mid-seventies. So, in some sense, his work played a prophetic role. Besides, bioeconomics, as Georgescu-Roegen called his new theoretical approach, is directly related to ecological economics, whose emergence dates back to the 1980s and which is also associated with Robert Costanza, Howard T. Odum, Herman Daly, and others (Sagoff, 2012). Like the bioeconomics of Georgescu-Roegen, modern ecological economics treats the economy as a subsystem of the ecosystem and focuses upon preserving natural capital (Costanza et al., 1997).

As for other fields of modern economics dealing with the Second Law of Thermodynamics, it is necessary to mention such a school of heterodox economics as thermoeconomics. Thermoeconomics deals with the concept of exergy and the efficiency of humanengineered energy systems, such as thermal power plants and chemical plants. The name 'exergy', just as we know it currently, was introduced in the early 1950s by the Slovene mechanical engineer Zoran Rant. He defined it as technical available energy that is externally useful work in opposition to the energy associated with the internal work of a system. So, in modern thermodynamics, the exergy of a system is the maximum useful work possible during a process that brings the system into equilibrium with a heat reservoir.

The word 'thermoeconomics' was coined by the American engineer Myron Tribus in the early 1960s when, together with R. Evans, he studied desalination processes and made exergy analysis, which led him to the idea of exergy costing and its applications to engineering economics (Valero \& Cuadra, 2009). According to Richard Gaggioli, who is one of the most prominent researchers in the field of thermoeconomics, using exergy content as a basis for cost accounting is important to management for pricing products and for their evaluation of profits; exergy is the only rational basis for evaluating fuels and resources, processes, devices, system efficiencies, dissipations and their costs, and the value and cost of systems outputs (Wall, 1986, p. 12).

Nowadays, thermoeconomics is a school of heterodox economics that applies the laws of thermodynamics to economic theory. Antonio Valero and César Torres Cuadra define it as 'the science of natural resources saving that connects physics and economics by means of the Second Law of Thermodynamics' (2009, p. 1). Thermoeconomic analysis combines economic and thermodynamic analysis by applying the concept of cost, originally an economic property, to exergy.

\section{Definition and properties of entropy}

Although entropy is associated primarily with the Second Law of Thermodynamics, for today there are different definitions of entropy, not always harmoniously combined with each other (Panchenkov, 2007, p. 153).

We can consider some of the most well-known approaches to the identification and characterization of the properties of entropy as next ones: 
1) Entropy as a measure of disorder. In particular, in this way entropy is treated in thermodynamics. According to the Second Law of Thermodynamics, the total entropy of any isolated thermodynamic system tends to either remain constant or increase over time, approaching a maximum value. This also means that an isolated system will gradually become more and more disordered.

2) Entropy as an energetic process. Entropy is associated with the process of the transformation of a high-quality energy (useful energy) into a low-quality energy ('lowgrade' energy), or with the process of dissipation of useful energy. Quality of energy, in its turn, is determined by its ability to do (useful) work.

In physics, work and entropy are inversely related. The principal way to decrease entropy is to do work through the expenditure of free energy. If free energy is available and is expended to do useful work, then the system becomes more orderly and entropy decreases. But if all available energy has been expended, then no more work can be done, and entropy will either remain constant or increase (Bailey, 2009).

3) Probabilistic approach. In thermodynamics the calculation of entropy is based on following Boltzmann's formula for an isolated system at thermodynamic equilibrium:

$$
S=k \ln W,
$$

where $k$ is the Boltzmann constant $\left(\mathrm{k}=1,38 \cdot 10^{-23} \mathrm{~J} / \mathrm{K}\right)$ and $W$ is the number of distinct microscopic states consistent with the given macro-state (such as a fixed total energy $E$ ). The Boltzmann formula shows the relationship between entropy and the number of ways the atoms or molecules of a thermodynamic system can be arranged. With the growth of the number of microscopic states $W$, associated with the macroscopic state of the system, entropy also increases. According to this approach, the maximal entropy characterizes the structure that consists of (a multitude of) homogeneous elements (Melnik, 2003). Also the maximum of the entropy function is the logarithm of the number of possible events, and occurs when all the events are equally likely (Carter, 2011, p. 30).

$W$ in Boltzmann's formula is sometimes called the thermodynamic probability since it is an integer greater than one, while mathematical probabilities are always numbers between zero and one.

In fact, Boltzmann's formula characterizes entropy as a probabilistic state of a system, that is, entropy is connected with probabilities. In his book Scientific Uncertainty and Information, Leon Brillouin wrote: 'Let us examine the evolution of some isolated system. This unstable system left on its own will be destroyed, gradually converting into more probable and stable states. At the same time both probability and entropy are growing' (Brillouin, 1964, p. 28).

4) Entropy as the opposite of information. Statistical entropy is a probabilistic measure of uncertainty or ignorance; information is the measure of reduction in that uncertainty. According to Brillouin, additional information about the system under consideration is a consequence of the reduction of entropy. Thus, the information is a negative contribution to entropy and is the equivalent of negentropy (negative entropy). He marked that despite entropy usually being described as measuring the amount of disorder in a physical system, a more precise statement is that entropy measures the lack of information about the actual structure of the system. This lack of information introduces the possibility of a great variety of microscopically distinct structures, which we are, in practice, unable to 
distinguish from one another. Since any one of these different microstructures can actually be realized at any given time, the lack of information corresponds to actual disorder in the hidden degrees of freedom.

It is also important to note that just as in thermodynamics the maximal entropy characterizes the structure that consists of (a multitude of) homogeneous elements, according to the concepts of information theory, the same type of a structure is related with zero (minimum) information (Melnik, 2003).

Curiously, that analogically with the law of diminishing marginal utility in economics, in information theory if we regard the sequence (a set) of homogeneous events, every next such an event (or a message) gives us less (or even zero) information than the previous event.

5) The invariance of the macro-state in relation to changes at the level of the microelements. In addition to the probabilistic approach, let us regard the example used by Stephen Hawking for description of the thermodynamic arrow of time. In his book $A$ Brief History of Time, in particular, he wrote:

The second law of thermodynamics results from the fact that there are always many more disordered states than there are ordered ones. For example, consider the pieces of a jigsaw in a box. There is one, and only one, arrangement in which the pieces make a complete picture. On the other hand, there are a very large number of arrangements in which the pieces are disordered and don't make a picture (Hawking, 1998, p. 148).

Similarly, we can consider a broken marble statue as an example of absolutely disordered system. The general value of a pile that consists of numerous marble fragments remains the same regardless of mutual arrangement of these fragments. Another example is a bad scientific article written without logical structure and the main constructive idea. If we can cut this text into pieces and put them together in random order, the general result (informative value for the reader) remains unchanged. In other words, the maximum level of entropy is characterized by the invariance of the macro-state in relation to changes at the level of the microelements.

\section{The use of the notion of entropy to characterize the viability of a market with perfect competition}

In short, even the brief observation of the main characteristics of entropy gives inspiration to make the parallels between entropy and some well-known economic conceptions. So we can compare the Second Law of Thermodynamics with the law of diminishing returns in economics, and to formulate the latter as a law of diminishing synergy and growing entropy (Voznaya, 2014, p. 58), since in both cases we deal with closed systems, dissipation (waste) of useful energy (resources) and diminishing productivity of a system. In the context of this parallelism, it is also important to mention the article of Candeal, Miguel, Induráin and Mehta, in which the authors reveal and mathematically demonstrate the similarity between the utility representation problem in economics and the entropy representation problem in thermodynamics (see Candeal et al., 2001). 
The notion of entropy can be also used for the study of some characteristics of a market. So some economists, in their attempts to explain market equilibrium or disequilibrium, apply to statistical physics and, thus, the fundamental principles of thermodynamics dealing with entropy (see e.g. Hannonen, 2014, p.123). In addition, since, among other definitions, entropy is a measure of disorder, it is natural to consider whether such a notion is applicable to analyze the character of order for market structures. From this point of view, it seems promising to examine the market of perfect competition, inasmuch as in modern economics this kind of market serves as the starting point in the comparative analysis of key market structures ${ }^{2}$.

The development of the model of perfect competition is associated with the names of Antoine Augustin Cournot and neoclassicists, such as William Stanley Jevons, Francis Ysidro Edgeworth, Alfred Marshall, John Bates Clark and Frank Knight (Stigler, 1957). In general, in the well-established modern interpretation, a market with perfect competition corresponds to the following basic conditions: a very large number of independently acting sellers; there is perfect knowledge and knowledge is freely available to all participants; a standardized product (perfectly competitive firms produce identical or homogeneous product); a single firm is said to be a price taker because no single firm can influence the market price, taking its price from the whole industry; there are no barriers to entry into or exit out of the market (McConnell \& Brue, 2008, p. 400).

Despite the fact that modern economics recognizes the unreality of a market with perfect competition, the latter still continues to set a peculiar benchmark. For instance, it is considered that in comparison with other market structures, a perfectly competitive economy uses the limited amounts of resources available to society in a way that maximizes the satisfaction of consumers; efficient use of limited resources necessitates both productive efficiency and allocative efficiency (McConnell \& Brue, 2008, p. 416). However, this traditional thesis can be questioned if in the study of economic structures we apply the definitions of entropy considered above. The fact is that we can primarily characterize perfect competition as the state of maximum entropy. I base such an assumption on the following arguments:

1) Probabilistic approach. A market with perfect competition is absolutely deconcentrated. It presents a very large number of sellers (and buyers) who offer completely identical goods and cannot affect the price of their products. An equilibrium price in such a market is established under the influence of supply and demand at the level of the average cost. Thus, the price differences here (between sellers) are minimal; theoretically they are absent. For this reason, in such a situation, if we consider a single firm that sells a certain product at a price $p_{o}$, there is a high probability that all such products in the market are being offered at the given price $p_{o}$. Or, from another point of view, there is a high probability that every firm sells goods at a given price $p_{e}$ and gets a given rate of profit.

As indicated above, the maximum entropy occurs when all of the possible states of a system are equally probable. In the case of a market with perfect competition, we also deal with events that are equally likely. Since all sellers in the market offer identical (homogeneous) goods at the same price, the buyer is indifferent about which seller he

\footnotetext{
2 This hypothesis was initially presented by the author of this article at a conference held in Kiev in 2009 (Vozna, 2009).
} 
deals with. This means that a firm in such a market cannot have constant customers. The probability that a consumer $B_{1}$ will buy a certain product from a seller $S_{1}$ equals the probability that he will buy the same product from another seller $S_{2}$ or from another seller $S_{3}$, and so on.

What is the general number of combinations of consumer distributions between sellers (firms)? If the number of sellers equals $\boldsymbol{n}$ and the number of buyers equals $\boldsymbol{m}$, the general number of these combinations $\boldsymbol{N}$ is equal to $\boldsymbol{n}^{\boldsymbol{m}}$. For example, if we have the situation of a pure monopoly, the number $\boldsymbol{N}$, regardless of the number of buyers, always equals 1 . But the number $\boldsymbol{N}$ is maximal for a market with perfect competition where both $\boldsymbol{n}$ and $\boldsymbol{m}$ are very large.

This numerical expression does not mean that a pure monopoly market is a structure with the minimum level of entropy (or, if it is so, that zero entropy is optative), but, in the same way as for a market with perfect competition, this seems to be in accordance with Boltzmann's probabilistic formula of entropy, considered above, because the maximum of the entropy function is the logarithm of the number of possible events, and occurs when all the events are equally likely.

2) A homogeneous structure. The market with perfect competition is a type of homogeneous system (structure). But according to the thermodynamics approach, the maximal entropy characterizes the structure that consists of (a multitude of) homogeneous elements.

3) From the information point of view. As a homogeneous structure a market with perfect competition must be characterized by zero information. As it was mentioned above, according to information theory, the equilibrium set of homogeneous elements in a state of chaos (absolute equilibrium) cannot have the information (Melnik, 2003, p. 206). Indeed, a market with perfect competition is also a market with perfect information inasmuch as information here is absent (has no value). Its absence is due to the fact that since the sellers offer completely identical products, they have nothing to hide from each other. The absolute absence of barriers to entry in this market also means a lack of information barriers. But minimum (zero) information corresponds to maximum entropy.

In modern economics, such a market, defined as perfect competition, is a rather theoretical construction and practically does not exist. In addition, it is also called 'the competition without competition' (Yudanov, 1997), because we cannot find here any price competition (since no one seller is able to influence a price, as well as modify it without adverse consequences for themselves) as well as non-price one (as goods here are standardized). It is noteworthy that Friedrich August Hayek, in his critique of the theory of perfect competition, wrote: 'what the theory of perfect competition discusses has little claim to be called 'competition' at all'; 'advertising, undercutting, and improving ('differentiating') the goods or services produced are all excluded by definition - 'perfect' competition means indeed the absence of all competitive activities' (Hayek, 2009).

However, considering a market with perfect competition as the structure with maximum entropy, we come to the same conclusion about the impossibility of its practical implementation. Moreover, if we accept the assumption that a market with perfect competition is characterized by maximum entropy, we can make following conclusions. 
1. Since entropy is a measure of disorder, a market with perfect competition is totally disorganized (unstructured). It is a chaotic, unsystematic market. That is why it is a shortlived (with a minimum density of time) formation.

2. As disorganized, such a market exists outside of any economic institutions (both formal and informal), whereas, according to Douglass North (1991, p. 97), 'institutions are the humanly devised constraints that structure political, economic and social interaction'. Thus, paradoxically, a perfectly competitive market cannot represent a market system (that is, it cannot function on the principles of the market economy) since it excludes, in accordance with logic, the property institutions too.

3. Being completely chaotic and unstructured, such a market cannot be considered as a system. This means that in achieving the maximum level of entropy, a system dies (ceases to exist). Thus, a perfectly competitive market characterized by the maximum level entropy cannot exist, basically.

4. If the increase of entropy means the reduction of the system's ability to do useful work, a market with the maximum level of entropy should be characterized by minimum productivity and functionality. In particular this means that every other economic structure characterized by a higher level of market (production) concentration can create (provide) a larger volume of utility (benefits) than the structure with perfect competition. 5. As a structure with a maximum level of entropy, a perfectly competitive market should be characterized by a lack of energy, that is, movement capacity. In our case it is not a mechanical motion, but processes of modification and/or development of a system. Thus, the market with perfect competition is incompatible with the processes of innovative changes.

These conclusions are not statements, but only assumptions; they are, rather, questions designed to encourage further research and discussion involving economic theorists as well as physicists. For example, I think Brillouin's thesis that the maximum entropy state is also the most stable (see above) requires further consideration. So, when a system under consideration reaches the maximum level of entropy, it stops being characterized as a system, since in this state of maximum entropy it is already destroyed (or it should be regarded as a dysfunctional system). This also means that dealing with living systems, including economic ones, it is not correct to associate their equilibrium state with such a kind of equilibrium as thermodynamic but rather with homeostasis (homeostasis is the term used in biology to describe the internal stability needed for survival of an organism). As for living systems characteristics, it is interesting to note that Erwin Schrödinger, a Nobel Prize-winning Austrian physicist, in his book What is Life (according to Lovelock, 2000) concluded that:

metaphorically, the most amazing property and characteristic of life is its ability to move upstream against the flow of time. Life is the paradoxical contradiction to the second law, which states that everything is, always has been, and always will be running down to equilibrium and death. Yet life is characterized by omnipresence of improbability that would make winning a sweepstake every day for a year seem trivial by comparison. (Lovelock, 2000, p. 23)

It does not mean that life violates the Second Law of Thermodynamics (Lovelock, 2000, p. 23); however the important characteristic of living systems is ability 'to decrease their internal entropy at the expense of free energy taken from the environment and subsequently rejected in degraded forms' (J.D. Bernal as cited in Lovelock, 2000, p. 25). 
If we regard the particular case of a market with perfect competition, in historical context, we can see its non-viability and, on the contrary, the trend of its displacement by market structures with a higher level of complexity and market concentration such as monopolistic competition, oligopoly, monopoly markets, and so on. From this point of view the appeal to the concept of entropy in general gives us additional arguments to assert that internally homogeneous systems, structures, and formations are unsustainable. At the same time the sample of market structures demonstrates how (living) systems tend towards complexity and higher information capacity. In other words, we do not observe here the movement system's elements toward the maximum entropy state as the most probable, but, opposite, the 'escape' from the state with maximum level of entropy to the structures with lower entropy.

It makes sense to note that Part III of the Frank H. Knight's famous work Risk, Uncertainty, and Profit has the title Imperfect Competition through Risk and Uncertainty (1921). His approach is very in tune with the proposed view at the perfectly competitive market as at the formation with maximum entropy, since uncertainty is related with entropy (as a measure of uncertainty). So the thesis about the 'escape' of markets from 'perfect' competition toward the types of imperfect competition, in order to reduce uncertainty and risk, also suggests the assumptions made above.

Finally, if we conclude that a market with perfect competition is totally disorganized and chaotic, in this case we must consider which type of disorder we are dealing with. One of the founders of synergetics, I. Prigogine, in his book Exploring Complexity, together with G. Nicolis, indicated at least two types of disordering. The authors wrote that order looks like a kind of compromise between two antagonistic factors. The first factor is a non-linear process like a chemical one, which continuously and uncoordinatedly sends innovative signals in the form of fluctuations. Another factor resembles the process of transportation because it catches, passes, and stabilizes these signals. The violation of the delicate balance between these two factors leads to qualitative change of state that occurs in a system. One of them is a chaotic state in which every element of a system acts independently. In another situation, we deal with a homeostatic, frozen state, which is characterized by complete homogeneity and in which all fluctuations are suppressed. Complexity, therefore, is constricted from both sides by two types of disorder (Nicolis \& Prigogine, 1989). In this sense, a market with perfect competition should be regarded from the standpoint of a dynamic and evolutionary process in economy, and, thus, this type of market can correspond to a specific phase of such a process.

As an example, we can consider a process of the diffusion of innovations or the life cycle of a product. Suppose that a certain company offers a completely new product in the market. As the sole distributor of this product, it has monopoly advantages and can receive a supernormal profit, but only until the moment when other firms also begin to supply the same (new) product. Increasing competition leads to a drop in prices, and the economic profit, derived by an innovator, just disappears. Eventually, if the diffusion of a certain innovation proceeds too (infinitely) rapidly and when other firms enter the market of an innovative product extremely easily - that is, without special information or technological, institutional, or other obstacles (barriers) - it undermines the very motivation of the individual firm to the innovation activity.

Therefore, we can conclude that such a market structure in which barriers to entry and exit do not actually exist, resources are infinitely mobile and the prices are too flexible, 
corresponds to the homeostatic type of disorder. According to Nicolis and Prigogine, this type of disorder means the frozen state of a system, which is characterized by complete homogeneity and in which all fluctuations (innovation signals) are suppressed.

\section{Conclusion}

Despite the contradictory interpretations of entropy, the correct use of this notion in economics can be quite productive, as it enriches the methodology of economic analysis. In this article I have tried to demonstrate how the application of the concept of entropy complements the analysis of some economic phenomena, making them more obvious or, conversely, unrealizable. The examples presented in the article - both classical examples and the model of perfect competition - demonstrate how the use of physical principles and laws can allow us to reinterpret some fundamental economic conceptions and, thus, to regard them from a new, and even unexpected, point of view.

As for the market with perfect competition, of course, we can have doubts about the transfer of a principle of thermodynamics into economic analysis and about the analogy between economic actors and gas molecules moving randomly in space. Nevertheless, in a similar way to a thermodynamic system (a state) with a maximum level of entropy, in a market with perfect competition we observe the same invariance of the macro-state in relation to changes at the level of the micro-elements. For instance, if we consider a thermodynamic homogeneous system (with maximal entropy in the state of equilibrium), the mutual swapping of particles ' $A$ ' and 'B' does not change the macro-state parameters (for example, the temperature). Similarly, in a market with perfect competition, the macro-state parameters are indifferent to the individual behavior of the market agents (for example, in relation to their output decisions or location).

Whereas the market with perfect competition is one type of homogeneous structure, the proposed conclusions give a real example of the use of the entropy concept for the analysis of other social and economic systems. For example, the entropic invariance (indifference) of a macro-state in relation to changes at the level of the micro-elements, described above, can also be observed in the case of a homogeneous social system such as a crowd, whose general behavior does not depend (or depends only weakly) on the characteristics of the individuals comprising the crowd.

Also, in my opinion, a similar entropic invariance characterized the socialist (communist) system in the imagination of Vladimir Lenin, who asserted that 'every cook must learn to rule the state'. In other words, this is a type of social system in which each member of society is easily replaced by another one. So, Newton turns into a cook and a cook easily becomes an 'outstanding' physicist. Naturally, the conversion of 'cooks' into 'Newtons' destroys the science itself. But precisely this mutual conversion between 'Newtons' and 'cooks' acquired a massive importance in the former USSR during the 'heroic' time of building communism and the period of the mass repressions of Stalinism. Thousands of brilliant scientists and cultural figures carried out unbearable primitive physical work in Stalin's camps, while the key positions in the economy, science, and the arts were often occupied by ignorant and incompetent people. Just as the increase in the entropy of a thermodynamic system is accompanied by the system's loss of the ability to do useful 
work, such monstrous substitution of people-cogs in the Stalinist system inevitably led to the low productivity of social labor.

In general, the use of the notion of entropy in economic analysis is capable of enriching traditional economic conceptions and, in addition, general systems theory and the synergetic paradigm, insofar as the economic systems concern problems of system stability, system openness, evolution and complexity.

\section{References}

Bailey, K. D. (1990). Social Entropy Theory. Albany, New York: State University of New York (SUNY) Press.

Brillouin, L. (1964). Scientific Uncertainty and Information. New York: Academic Press.

Burketta, P., \& Fosterb, J. B. (2008). "The Podolinsky Myth: An Obituary Introduction to 'Human Labour and Unity of Force', by Sergei Podolinsky", Historical Materialism, Vol. 16, p. 115-161, available at: http://sociology.uoregon.edu/files/2014/04/FosterBurkett_Foster_2008_Historical-Materialism-26ojqae.pdf

Carter, T. (2011). "An Introduction to Information Theory and Entropy", available at: http://www.fi.muni.cz/usr/staudek/infteo/info-lec.pdf

Candeal, J. C., Miguel J. R. De, Induráin, E., Mehta,G. B. (2001). "Utility and entropy", Economic Theory, Vol. 17, issue 1, p. 233-238

Costanza, R., Cumberland, J., Daly, H., Goodland, R., Norgaard, R. (1997). An Introduction to Ecological Economics. Boca Raton, Florida: St. Lucie Press.

Dima, B., Dima, S. M., Barna, F., Năchescu, M. (2014). "How to Trade Using the (Shannonian) Transfer Entropy? An Application for Central and Eastern European Markets", Economic computation and economic cybernetics studies and research, Vol. 48, Issue 2, p. 57-73

Georgescu-Roegen, N. (1971). The Entropy Law and the Economic Process. Cambridge, MA: Harvard University Press.

Georgescu-Roegen, N. (1975). "Energy and Economic Myths", Southern Economic Journal, Vol. 41, No. 3.

Georgescu-Roegen, N. (1986). "The Entropy Law and the Economic Process in Retrospect", Eastern Economic Journal, Vol. XII, No. 1, p. 3-25.

Gowdy, J., \& Mesner, S. (1998). "The Evolution of Georgescu-Roegen's Bioeconomics", Review of Social Economy, Vol. LVI, No. 2, p. 136-156.

Hannonen, M. (2014). "Urban Housing Policy Considerations: Perspectives from the Finnish Housing Market”, Journal of Heterodox Economics, Vol. 1, № 2, 114-130, available at: http://www.jheec.com/assets/files/Issue\%202/jhec_1_2.protected.pdf

Hawking, S. W. (1998). A brief history of time. Bantam: New York. 
Hayek, F. A. (2009 [1948]). The Meaning of Competition. In F. A. Hayek, Individualism and Economic Order, [Ludvig von Mises Institute], available at: https://mises.org/library/meaning-competition

Korniychuk, L. Ya. (2000). The Life and Activity of S. A. Podolyns'ky. In S. A. Podolyns'ky, Vybrani tvory [Selected Works]. Kyiv: [Kyiv National Economic University Press]. [In Ukrainian]

Knight, F. H. (1921). Risk, Uncertainty, and Profit, available at: http://www.econlib.org/library/Knight/knRUP.html

McConnell, C. R., \& Brue S.L. (2008). Economics: Principles, Problems, and Policies (17th ed.). New York: McGraw-Hill/Irwin.

Lovelock, J. (2000). The Ages of Gaia: A Biography of our Living Earth (Second ed.), Oxford: Oxford University Press.

Martinez-Alier, J., \& Naredo, J. M. (1982). “A Marxist Precursor of Energy Economics: Podolinsky", The Journal of Peasant Studies, Vol. 9, No. 2, p. 207-224.

Melnik, L. (2003). Printsipial'nyje osnovy razvitiya [The fundamental basis for development]. Sumy: University Book. [In Russian]

Munda, G. (2016). "Beyond Welfare Economics: some methodological issues", Journal of Economic Methodology, 23, 185-202.

Nicolis, G., \& Prigogine, I. (1989). Exploring Complexity: An introduction. New York: W.H. Freeman.

North, D. (1991). "Institutions", The Journal of Economic Perspectives, Vol. 5, No. 1, p. 97112.

Panchenkov, A. N. (2007). Ekonofizika [Econophysics]. N. Novgorod: OOO Tipografiya Povolzhie. [In Russian]

Podolyns'ky, S. A. (2000). Vybrani tvory [Selected Works]. Kyiv: [Kyiv National Economic University Press]. [In Ukrainian]

Sagoff, M. (2012). "The Rise and Fall of Ecological Economics", available at: http:// http://thebreakthrough.org/index.php/journal/past-issues/issue-2/the-rise-andfall-of-ecological-economics

Stigler, G. J. (1957). "Perfect Competition, Historically Contemplated", Journal of Political Economy, 65, 1, 1-17.

Valero, A., \& Torres C. (2009). "Thermoeconomic Analysis”, in C. A. Frangopoulos (Ed.), Exergy, Energy System Analysis and Optimization (Vol. II). Oxford, UK: EOLSS Publishers/UNESCO, available at: http://www.eolss.net/samplechapters/c08/e3-19-02-00.pdf

Vozna, L. (2009, April). The Notion of Entropy in the Analysis of Market Structures' Stability (on the example of a perfect competition market). Paper presented at the conference Physical Economy of Kyiv National Economic University of Vadym Get'man (pp. 332-337), Kiev [in Ukrainian], available at: http://ir.kneu.edu.ua:8080/bitstream/2010/11244/1/332-337.pdf

Voznaya, L., 2014, Obschaya teoriya ustoychivosti sotsial'no-ekonomicheskih sistem [The general theory of the social-economic systems stability], Izdatel'stvo Yevenok, Zhitomir [in Russian]. 
Wall, G. (1986). Exergy - a Useful Concept. Göteborg: Physical Resource Theory Group, available at: http://www.exergy.se/ftp/thesis.pdf

Yudanov, A. Yu. (1997). "The Theory of Competition: Applied Aspects", Mirovaya Ekonomika i Mezhdunarodnyie Otnosheniya [World Economy and International Relations], 6, 48-55. [In Russian] 